\title{
THE IMPACT OF COMBUSTOR TURBULENCE ON TURBINE LOSS MECHANISMS
}

\author{
Masha Folk \\ University of Cambridge \\ Cambridge, UK
}

\author{
Robert J. Miller \\ University of Cambridge \\ Cambridge, UK
}

\author{
John D. Coull \\ University of Cambridge \\ Cambridge, UK
}

\begin{abstract}
A blade row which is located downstream of a combustor has an extremely high turbulence intensity at inlet, typically above $10 \%$. The peak turbulent length scale is also high, at around $20 \%$ of the chord of the downstream blade row. In a combustor, the turbulence is created by impinging jets in cross flow. This may result in the turbulence being anisotropic in nature. The aim of this paper is to investigate the effect of combustor turbulence on the loss mechanisms which occur in a turbine blade row. The paper has a number of important findings. The combustor turbulence is characterized and is shown to be isotropic in nature. It shows that, when no pressure gradient is present, combustor turbulence increases the loss of a turbulent boundary layer by $22 \%$. The mechanism responsible for this change is shown to be a deep penetration of the turbulence into the boundary layer. It shows that the presence of combustor turbulence increases the profile loss and endwall loss in the turbine cascade studied by $37 \%$ and $38 \%$, respectively. The presence of combustor turbulence also introduces a freestream loss resulting in the total loss of the turbine cascade rising by $47 \%$. When these loss mechanisms were applied to the vane alone, of an engine representative high pressure turbine, it was found to result in a $1.3 \%$ reduction in stage efficiency.
\end{abstract}

\section{INTRODUCTION}

In a gas turbine engine, the combustor upstream of the high pressure turbine generates turbulence with impinging jets in crossflow. Measurements downstream of a combustor show that turbulence intensities at the inlet of a downstream blades row typically exceed $10 \%$ [1-3]. This is very different from the typical grid turbulence of around $1 \%$ to $4 \%$ used in most turbine cascade and stage testing. This difference raises the question of how the presence of combustor turbulence changes the loss mechanisms in the downstream turbine.

The impact of combustor turbulence on a downstream turbine cascade is shown in Figure 1. The figure shows a traverse taken using a pneumatic probe mounted $21 \%$ axial chord downstream of the blade trailing edge. The results will be discussed in detail later in the paper. However, it can be clearly seen that the presence of combustor turbulence has a major effect on both the width of the wake at $50 \%$ span and on the structure of the endwall secondary flow. The aim of this paper is to take an approach similar to Denton [4] to investigate the impact of combustor turbulence on a number of loss mechanisms which occur in a turbine blade row mounted downstream of a combustor.

The development of a combustor-style turbulence generator for cascade testing was first reported by Ames and Moffat [5]. A number of studies have since investigated the impact of combustor turbulence on downstream components [613]. These studies have mainly focused on the effect of combustor turbulence on wall shear stress and heat transfer on a flat plate. The papers report that the presence of combustor turbulence causes an increase in wall shear stress of $10 \%$ to $34 \%$. A number of papers also investigate the effect of turbulence on the development of the boundary layer [14-18]. These studies

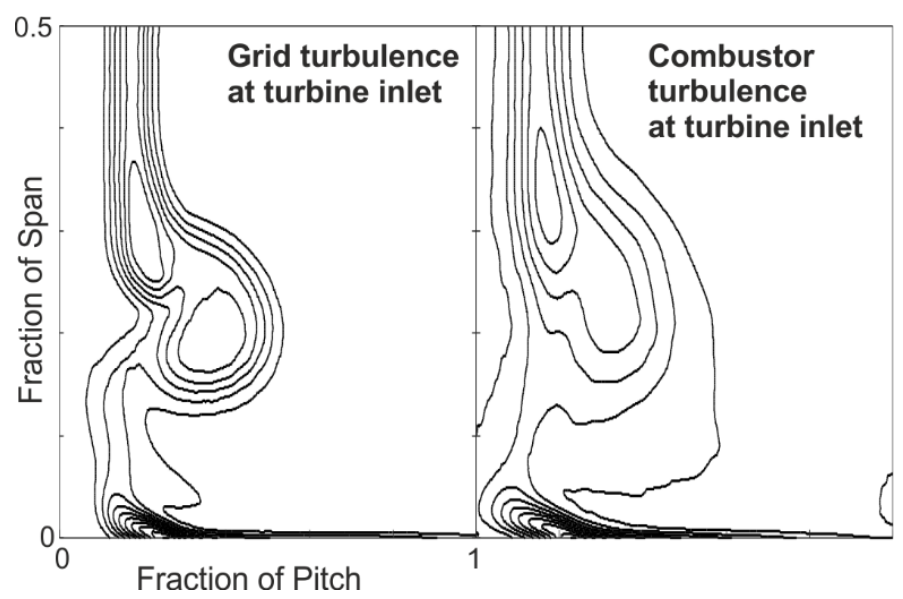

Figure 1: Contours of measured loss coefficient at $21 \%$ axial chord downstream of a turbine cascade. Contour intervals are $5 \%$ of exit dynamic head. 
report that the combustor turbulence reduces the shape factor of the boundary layer, creating a 'fuller' velocity profile. These papers show that combustor turbulence has the ability to penetrate deep into the boundary layer.

Several studies have looked at the effect of combustor turbulence on turbine cascades $[7,8,11]$. A $16 \%$ to $27 \%$ increase in skin friction was measured on the blade surface in $[7,8]$. Chowdhury et al. [11] is the only study to investigate the effect of combustor turbulence on the loss coefficient of a turbine cascade. They showed that the loss coefficient of the cascade rose by between $38 \%$ and $50 \%$ depending on Reynolds number.

This paper takes a different approach. The paper focuses on the individual loss mechanisms which occur in a turbine blade row and identifies the impact of combustor turbulence on each.

\section{METHODS}

\subsection{Turbulence Generators}

Two turbulence generators were used in the testing: a combustor simulator and a turbulence grid. The design of the combustor turbulence generator, shown in Figure 2, was based on the work of Kingery and Ames [13]. In the design, 1/3 of the mass flow enters through slots in the back wall and $2 / 3$ from the side through impingement jets. A turbulence grid installed in a rectangular duct replaced the combustor simulator for low turbulence tests. The grid was designed following Roach [19] to have a lower turbulence intensity than the combustor turbulence but a similar length scale. Inlet turbulence was characterized using a hotwire with two parallel wires inclined at $\pm 45^{\circ}$ to the flow. The measured turbulence intensity and length scale are presented in Section 3.

\subsection{Working Sections}

Two downstream working sections were used. The first working section was a linear turbine cascade and the second was a flat plate. The Harrison cascade [20] was chosen for the turbine section, because of its previous extensive study [20-23]. The blade is specifically designed to have large secondary so that the

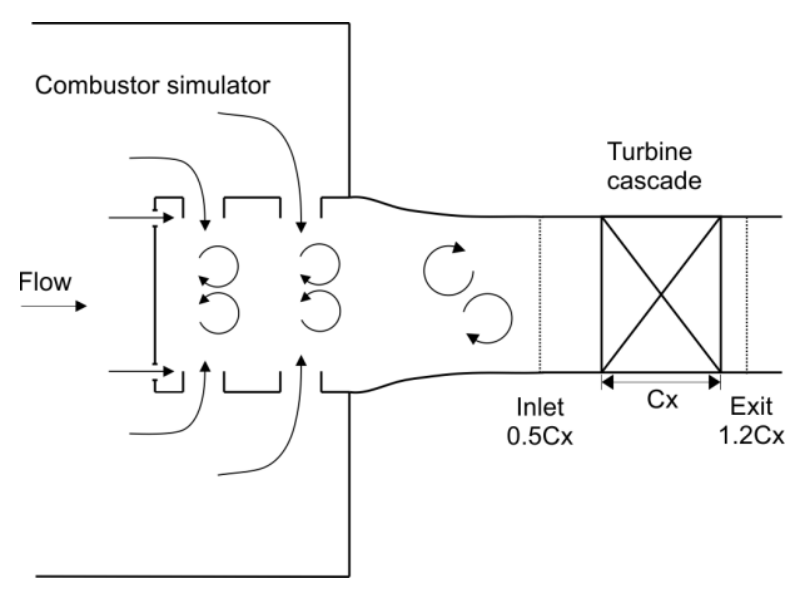

Figure 2: Schematic of the combustor simulator upstream of the turbine cascade changes in secondary flow can be studied with great fidelity.

The cascade has four blades with a span of $300 \mathrm{~mm}$, true chord of $278 \mathrm{~mm}$, and axial chord of $222 \mathrm{~mm}$. Inlet flow was $40^{\circ}$ and exit flow was $-65.5^{\circ}$ relative to axial. The inlet plane is located $50 \%$ axial chord upstream of the leading edge, and the exit plane is located $21 \%$ axial chord downstream of the trailing edge. The trailing edge thickness is $2.2 \mathrm{~mm}$. The Reynolds number of the flow, based on true chord and exit velocity, was 800,000 with an exit Mach number of 0.14 . The loss coefficient of the two central blades was within $3 \%$ for all cases.

The pressure distributions for the combustor and grid cases are shown in Figure 3. A miniature five-hole probe (manufactured by Cambridge Aerothermal) was used to measure total pressure at a number of planes upstream, within and downstream of the cascade. The locations of the planes within the cascade are marked in Figure 3. The uncertainty of the passage total pressure loss coefficient, $\overline{Y_{p}}$ (non-dimensionalized by the turbine exit dynamic pressure) was determined to be \pm 0.003 . The uncertainty of the profile loss coefficient was determined to be \pm 0.001 of exit dynamic head in grid turbulence and \pm 0.0025 of exit dynamic head in combustor turbulence. The mid-span boundary layer was traversed using a standard boundary layer hot wire.

The second working section was a flat plate. The aim of these tests was to determine the effect of combustor turbulence on a boundary layer with no acceleration or surface curvature. The plate is one meter long and was located in the middle of the working test section (cascade midspan in Figure 2). The leading edge was a 6:1 ellipse, and the boundary layer was tripped downstream of the leading edge. Measurements were made both with a single component boundary layer hotwire and with a two component hotwire probe. The uncertainty of the boundary layer integral parameters $\left(\delta^{\star}, \theta, \delta_{e}\right)$ was determined to be within $\pm 1 \%$ in grid turbulence and $\pm 2.3 \%$ in combustor turbulence. The measured mean velocity profile was fit to a canonical boundary layer following the method of Rodríguez-López et al. [24]. An output of this fitting method is the shear stress velocity, $u_{\tau}$, which is used to calculate skin friction. This procedure of determining

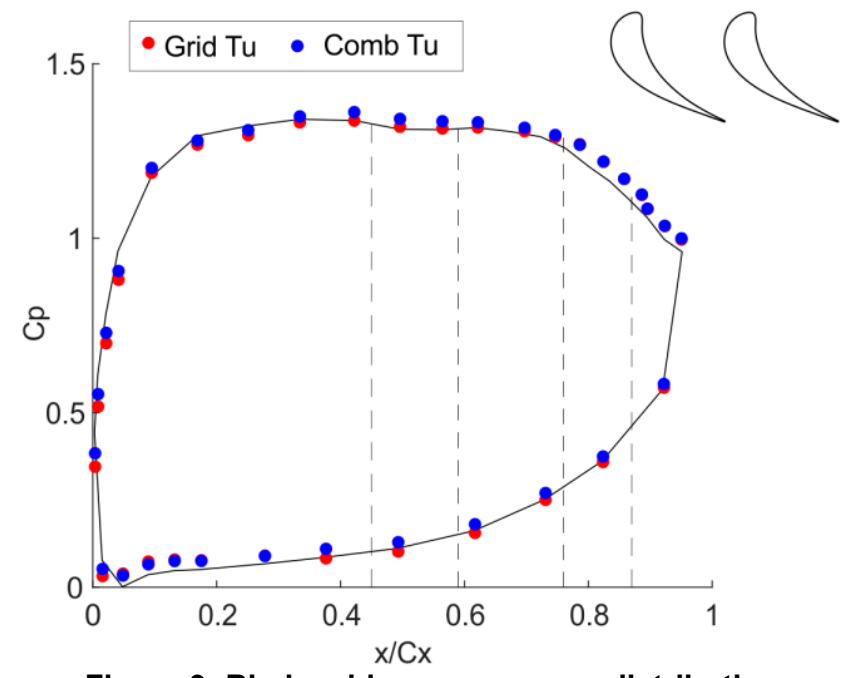

Figure 3: Blade mid-span pressure distribution 
skin friction has been recently validated against oil film interferometry in high free stream turbulence by Esteban et al. [25]. The uncertainty of skin friction measured directly from the near wall velocity profile was determined to be within $\pm 3.6 \%$.

\subsection{Total Pressure}

In an incompressible flow with high turbulence, it can be shown analytically [26] that if the flow is brought to rest reversibly and with zero work extraction, the total pressure, $P_{0 \text { rev }}$, is given by:

$$
P_{0 \text { rev }}=P+\frac{1}{2} \rho\left(U_{i}^{2}+\overline{u_{l}^{2}}\right)
$$

If it is assumed that all of the turbulent kinetic energy is dissipated as the flow is brought to rest, then the total pressure, $P_{0}$, is given by:

$$
P_{0}=P+\frac{1}{2} \rho\left(U_{i}^{2}\right)
$$

For incompressible flow, the total pressure represents the power per unit volume flow rate which can be extracted from the flow. In this paper, it is assumed that the second definition of total pressure, $P_{0}$, represents the power per unit volume flow rate which can be extracted from the flow with a turbine. This definition has been chosen because the length scale of a typical turbine blade is much larger than the length scale of the turbulence; therefore, the blade is not able to extract useful work from the turbulent kinetic energy. In reality, the recovery process of turbulent kinetic energy is very complex and, for brevity, will not be discussed here. In this paper, loss is therefore defined as anything that decreases $P_{0}$.

The presence of high levels of turbulence also affects the accuracy of the total pressure measured by a pneumatic probe. A recent study published by the International Collaboration on Experimental Turbulence [27] showed that in flows with high free stream turbulence, the measured total pressure, $P_{0 M}$, is:

$$
P_{0 M}=P_{0}+\frac{1}{2}\left(\overline{u_{x}^{2}}\right)
$$

where $u_{x}$ is the fluctuating velocity component in the axis aligned with the head of the probe. This equation was used to correct all of the total pressure measurements. It should, however, be noted that the correction is small. The largest correction to the total pressure coefficient (non-dimensionalized by the turbine exit dynamic pressure) is $0.13 \%$. The size of this correction may seem small to the reader, especially when the turbulence intensity is so high. However, the largest turbulence intensities are at the vane inlet where the kinetic energy of the mean field is low.

\section{NATURE OF INLET TURBULENCE}

In this section, three specific questions are answered regarding the nature of the turbulence at inlet plane of the turbine control volume: What is the turbulence intensity? Is the turbulence isotropic? Is the boundary layer response to the longer length scale in the combustor turbulence quasi-steady?

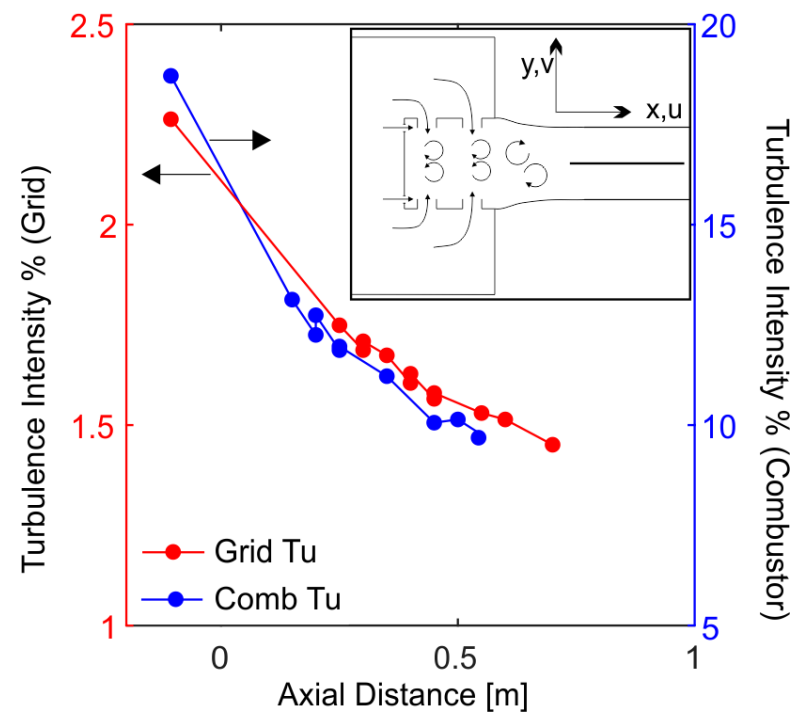

Figure 4: Axial development of free stream turbulence measured over the flat plate

\subsection{What is the Turbulence Intensity?}

At the inlet plane of the turbine control volume, the combustor turbulence intensity is $10 \%$ and the grid turbulence intensity is $1.3 \%$. The axial decay in turbulence over the flat plate is shown in Figure 4. It should be noted that the leading edge of the flat plate in Figure 4 is located at an axial location of 0 . In the same coordinate system, the inlet plane of the turbine control volume is located at an axial location of $0.67 \mathrm{~m}$.

\subsection{Is the Turbulence Isotropic?}

Figure 5 shows the components of turbulence measured at the inlet plane of the turbine control volume. The $\mathrm{x}$-axis zero is the center of the test section, where the flat plate was located. It is also the midspan of the turbine cascade.

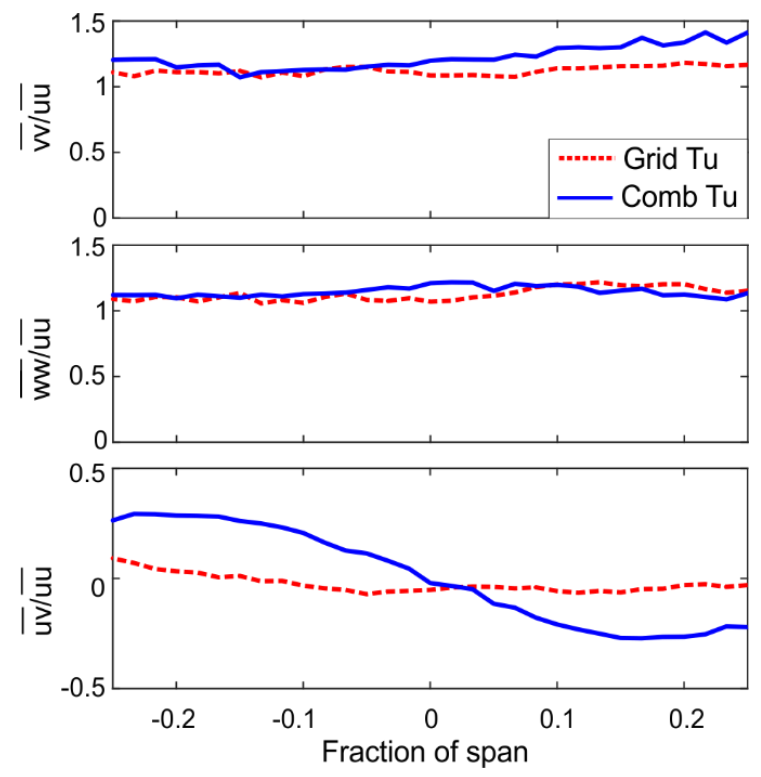

Figure 5: Measurements of anisotropy at the inlet 
The top two subplots in Figure 5 show the ratio of spanwise and pitchwise fluctuations, $\overline{v v}$ and $\overline{w w}$, to streamwise fluctuations, $\overline{u u}$. The ratio in each plot is close to one in both grid and combustor turbulence. This indicates that by the exit of the combustor, the turbulence is remarkably isotropic in nature.

The bottom subplot in Figure 5 shows the variation in Reynold's stress, $\overline{u v}$. The grid turbulence has a near zero value. The combustor turbulence Reynolds stress is not zero, and it exhibits an antisymmetric shape. This is caused by the opposing direction of the impinging jets in the combustor simulator. The magnitude of this term is small, but it indicates that small coherent structures are still present in the combustor turbulence.

\subsection{Is the Boundary Layer Response Quasi-Steady?}

The integral length scale of combustor turbulence $(22 \%$ of turbine chord) is larger than typical laboratory grid turbulence ( $\sim 2 \%$ of turbine chord). This means that the characteristic time scale, imposed by the combustor turbulence on the boundary layer, is 10 times larger than typical laboratory grid turbulence. This raises the question of whether the boundary layer response to this larger time scale is in fact 'quasi-steady'.

The non-dimensional frequency of importance is $\delta^{2} \omega / \nu$. This is the ratio of the time taken for momentum or vorticity to diffuse through the boundary layer, order $\delta^{2} / v$, to the time taken for the flow in freestream to change, order $1 / \omega$. Typically, if $\delta^{2} \omega / v<0.1$, a 'quasi-steady' approximation of the boundary layer is considered acceptable.

Figure 6 shows energy spectra of the grid and combustor turbulence at the inlet plane of the turbine control volume. (NB $\delta$ was set at the value on the blade at mid-chord, $R e_{\theta}=670$ ). The uncertainty bands represent the range of turbulent viscosity in a boundary layer. The peak in the spectrum is observed to occur at $\delta^{2} \omega / v \sim 10$. This shows that the diffusion time scale is 10 times the characteristic time scale associated with the large turbulent eddies in the freestream.

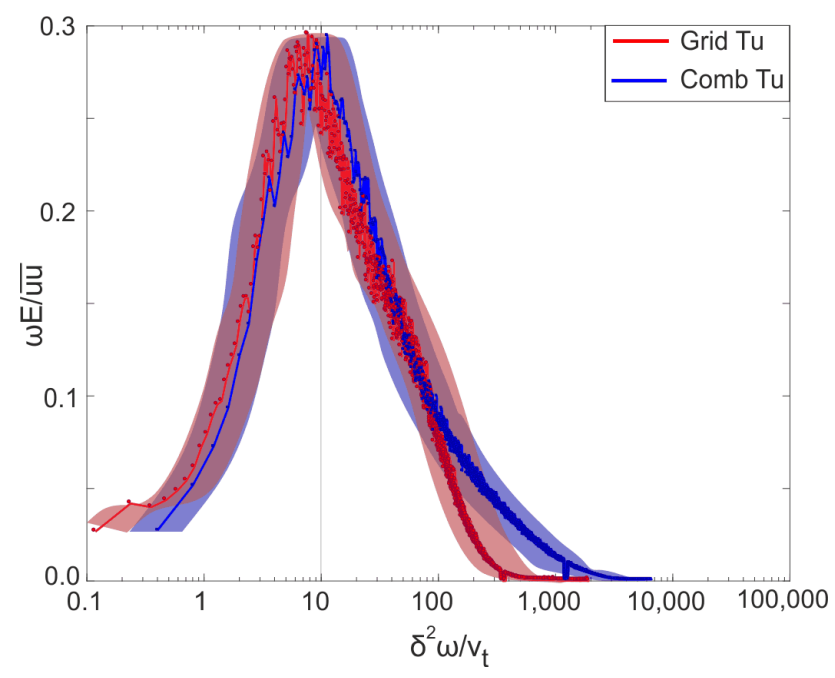

Figure 6: Energy spectra of turbulent kinetic energy measured in combustor and large-scale grid turbulence

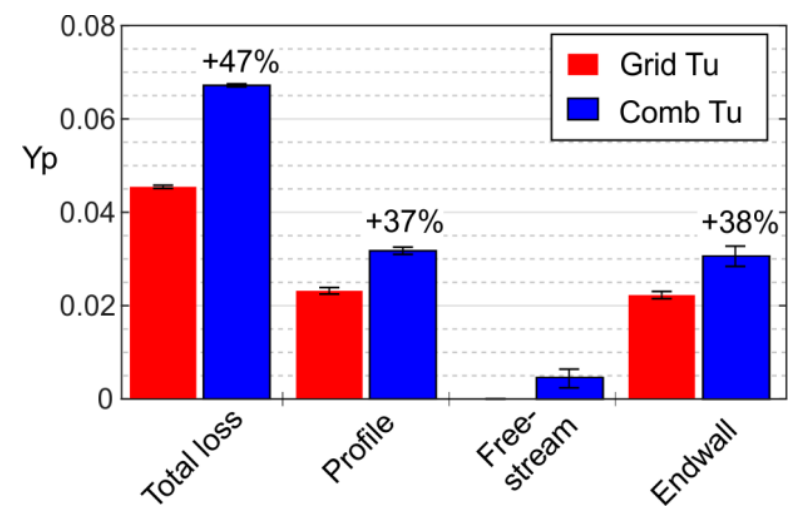

Figure 7: Measured loss on a turbine cascade

In conclusion, the response of the boundary layer to combustor turbulence is far from 'quasi-steady'. Telionis [28], in his review paper on unsteady boundary layers, laments that even the most advanced models "do not seem to predict even the physical tendencies correctly." In this paper, the response of the boundary layer to combustor turbulence will be measured experimentally.

\section{TOTAL CASCADE LOSS}

The total loss coefficient of the turbine cascade, with both grid and combustor turbulence, is shown in Figure 7. The loss is calculated from the difference in the mass-averaged total pressure from the inlet to the exit of the turbine control volume. The figure shows that the presence of combustor turbulence causes the loss of the turbine cascade to rise by $47 \%$.

\section{Table 1: Measured turbine total pressure loss coefficient}

\begin{tabular}{|c|c|c|}
\hline & Grid Tu & Comb Tu \\
\hline Profile & 0.0232 & 0.0318 \\
\hline Free stream & 0.0000 & 0.0047 \\
\hline Endwall & 0.0223 & 0.0307 \\
\hline Total loss & $\mathbf{0 . 0 4 5 4}$ & $\mathbf{0 . 0 6 7 2}$ \\
\hline
\end{tabular}

This rise in loss was measured at a Reynolds number of 800,000 . This is similar to the $50 \%$ rise in loss measured on a very different design of vane at a Reynolds number of 1,000,000 by Chowdhury et al. [11]. This implies this large rise in loss is not specific to the blade studied.

Figure 7 and Table 1 include a breakdown of the total loss into profile loss, freestream loss and endwall loss. The method by which the loss is decomposed is discussed in the following section. It is, however, interesting to observe that the presence of combustor turbulence raises the profile loss and endwall loss by $37 \%$ and $38 \%$, respectively. In addition, the presence of combustor turbulence is found to cause a non-zero freestream loss. The physical cause of this will be discussed in the following sections. The rest of the paper will focus on the individual loss mechanisms and will identify the impact of combustor turbulence on them. The simpler case of a flat plate is considered first. 


\section{LOSS MECHANISMS IN BOUNDARY LAYERS}

The aim of this section is to determine the change in entropy generation in a turbulent boundary layer due to the presence of combustor turbulence. The experiments were undertaken on a flat plate to ensure that acceleration and curvature was removed from the problem. The presence of high freestream turbulence changes the formulation of the integral boundary layer equations. This is discussed in detail in Appendix B.

It is important to understand how the boundary layer loss presented in this section should be interpreted. The freestream has a non-zero loss (see Figure 7). The boundary layer loss should be interpreted as the loss relative to this freestream loss.

Figure 8 shows the impact of combustor turbulence on the flat plate boundary layer $\left(R e_{\theta}=2,000\right)$. The presence of combustor turbulence can be seen to reduce the shape factor of the boundary layer from $H_{12}=1.43$ to 1.30 . It will be shown that this results from a deep penetration of the combustor turbulence into the boundary layer.

\subsection{Skin Friction}

The skin friction coefficient for the case of grid turbulence is shown in Figure 9. The red circles show the direct method of determining $C_{f}$ from the experimental measurements. This direct method involves fitting a canonical velocity profile to the measured velocity and using the resulting $u_{\tau}$ to calculate skin friction. The indirect method is determined from the rate of growth of momentum thickness $\left(C_{f}=2 d \theta / d x\right)$. The two methods agree to within $4 \%$. Figure 9 also includes the $C_{f}$ calculated from DNS [29]. The DNS is for a flat plate with no freestream turbulence. The experiments and DNS are in close agreement.

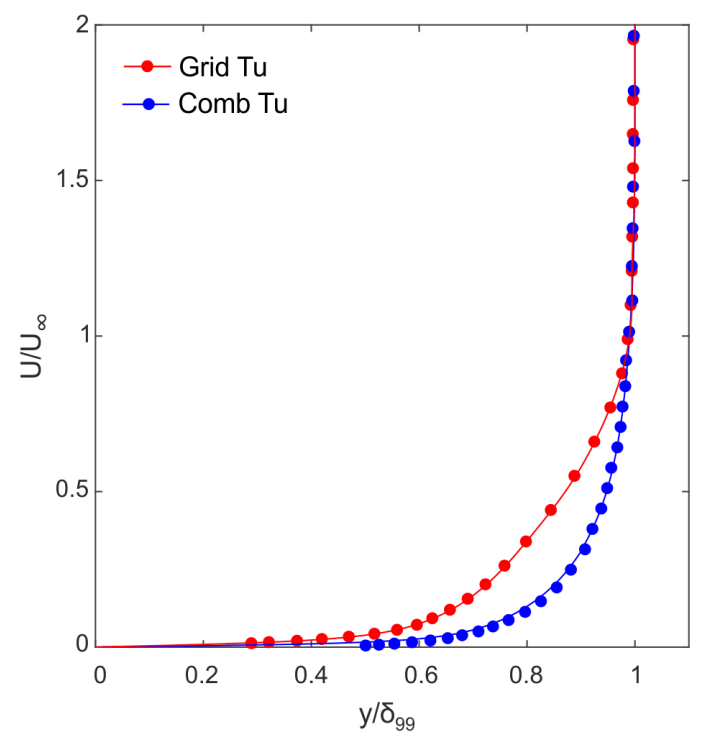

Figure 8: Boundary layer profile measured on a flat plate in grid and combustor turbulence $\left(R e_{\theta}=2,000\right)$

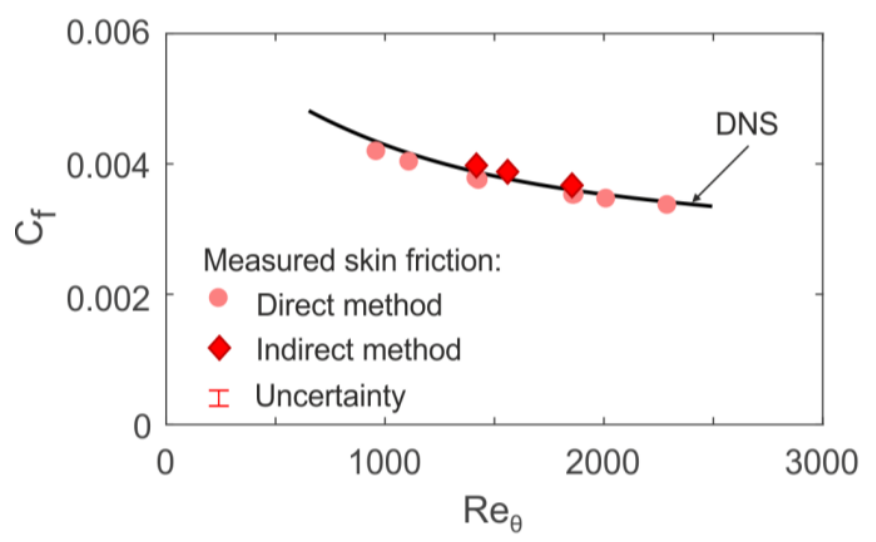

Figure 9: Skin friction variation on a flat plate (Measurements in grid turbulence and DNS with no freestream turbulence [29])

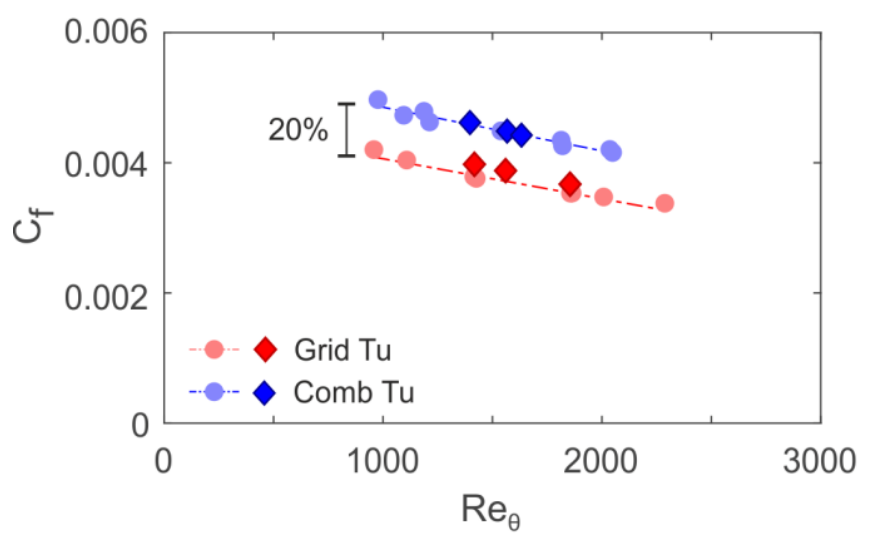

Figure 10: Skin friction on a flat plate with grid and combustor turbulence

Figures 10 and 11 show that the presence of combustor turbulence causes a $20 \%$ rise in $C_{f}$ and a $9 \%$ reduction in shape factor $H_{12}$ of the boundary layer. In summary, the presence of combustor turbulence causes a fuller boundary layer profile with a corresponding rise in skin friction.

\subsection{Dissipation Coefficient}

The dissipation coefficient for the case of grid turbulence is shown in Figure 12. The red points show $C_{D}$ calculated from the experimental measurements, and the black line shows $C_{D}$ calculated from the DNS [29]. The experiment and DNS are in close agreement. In Figure 12, the black dashed line shows the correlation for $C_{D}$ given by Schlichting [31]. The trend of the correlation can be seen to disagree with the present experiments and DNS.

Figures 13 and 14 show that the presence of combustor turbulence causes a $22 \%$ rise in $C_{D}$ and a $4 \%$ drop in $H_{23}$. The blue solid line in Figure 13 shows best fit to DNS scaled by an empirical factor of 1.22 . 


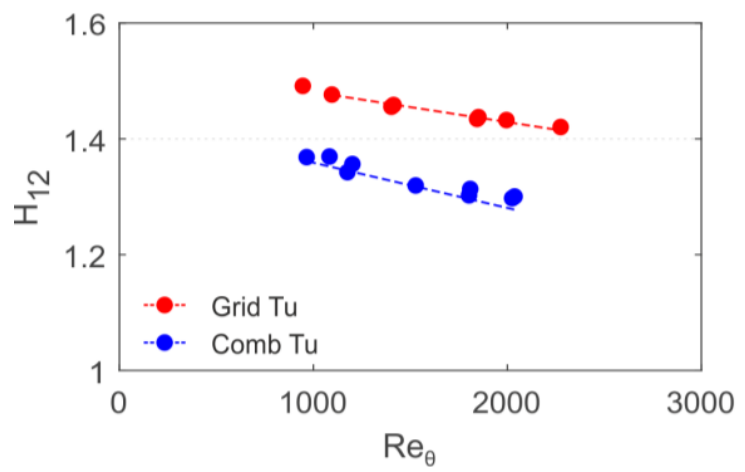

Figure 11: Shape factor, $H_{12}$, on a flat plate with grid and combustor turbulence

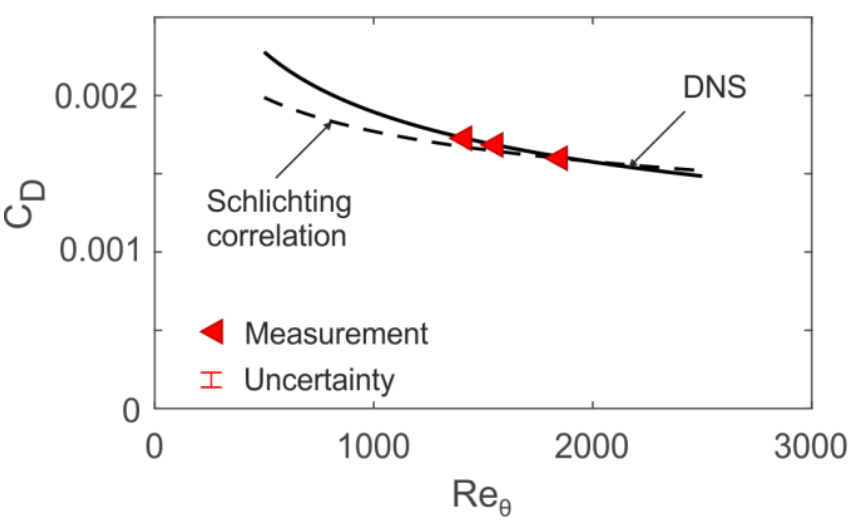

Figure 12: Dissipation coefficient variation on a flat plate

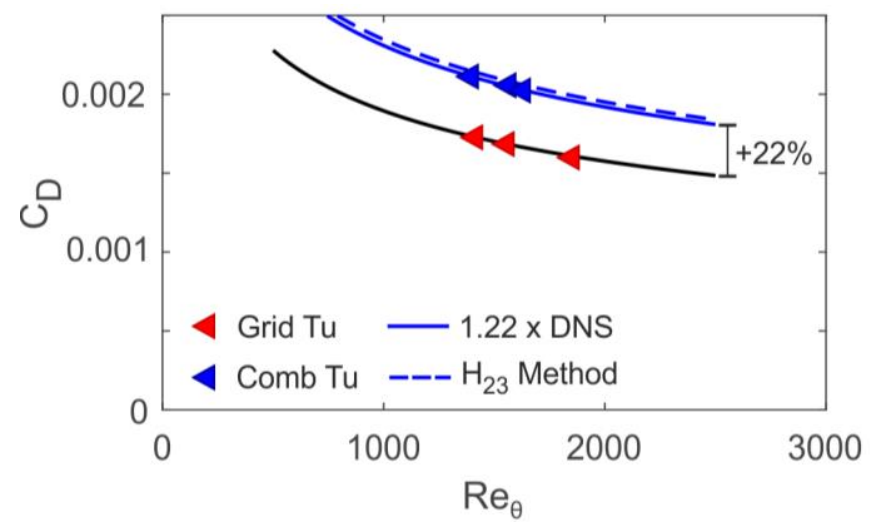

Figure 13: Dissipation coefficient on a flat plate with grid and combustor turbulence

A second method of calculating the rise in $C_{D}$ due to the presence of combustor turbulence is through the measured change in $H_{23}$ and the measured change in $C_{f}$.

$$
C_{D}=\frac{C_{f}}{4 H_{23}}-\frac{\theta \frac{d H_{23}}{d x}}{H_{23}^{2}}
$$

The second term in Equation 4 is five orders of magnitude smaller than the first term and so can be ignored. The dashed blue line in Figure 13 is $C_{D}$ calculated from Equation 4. This second

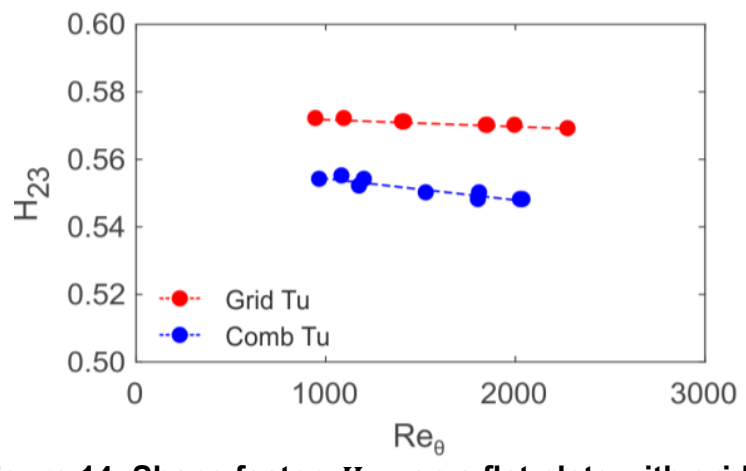

Figure 14: Shape factor, $H_{23}$, on a flat plate with grid and combustor turbulence

method shows that the presence of combustor turbulence causes a $24 \%$ rise in dissipation coefficient.

The close agreement between the two methods for calculating the rise in $C_{D}$, shown in Figure 13, gives great confidence that the rise in $C_{D}$ due to combustor turbulence has been correctly determined.

In conclusion, the presence of combustor turbulence increases the dissipation coefficient of a turbulent boundary layer (zero pressure gradient and curvature) by $22 \%$.

\subsection{Physical Mechanism}

The power spectrum of the flat plate boundary layers shown in Figure $8\left(R e_{\theta}=2000\right)$, for the cases of grid and combustor turbulence, are shown in Figure 15.
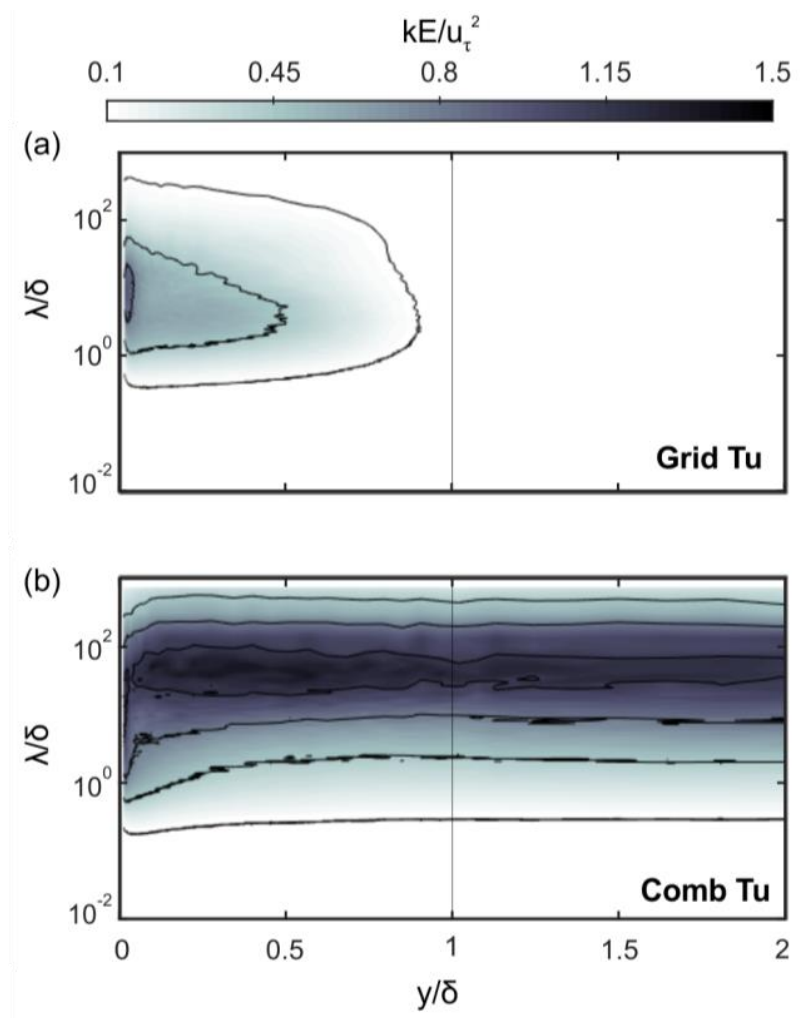

Figure 15: Power spectrum of turbulent kinetic energy in a flat plate boundary layer $\left(\operatorname{Re}_{\theta}=2,000\right)$ 


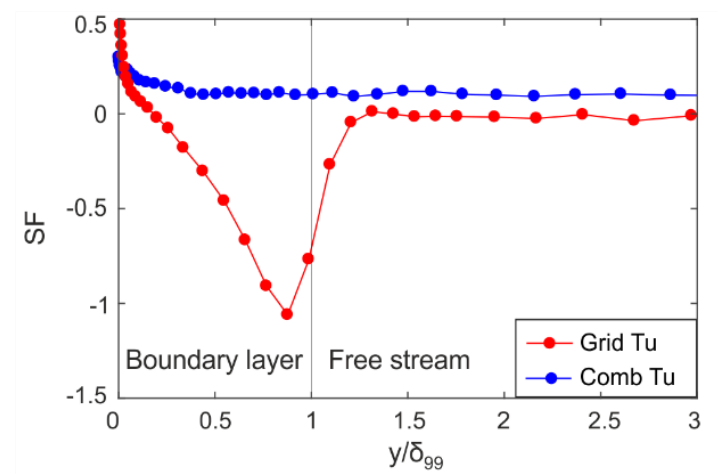

Figure 16: Skewness factor of a flat plate boundary layer $\left(R e_{\theta}=2,000\right)$ with grid and combustor turbulence

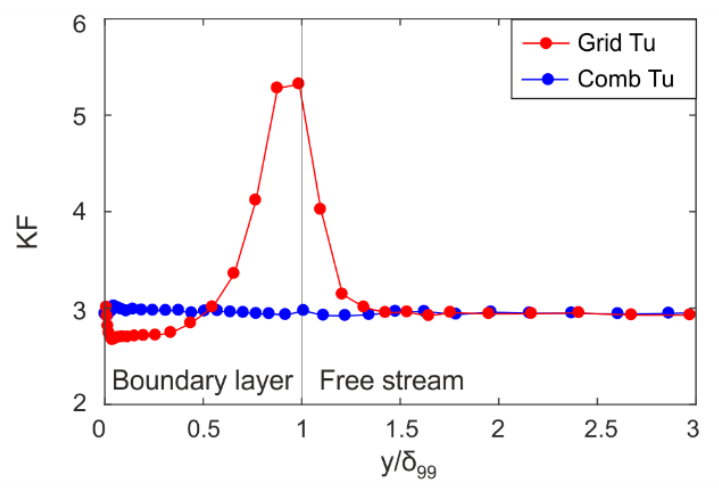

Figure 17: Kurtosis factor of a flat plate boundary layer $\left(R e_{\theta}=2,000\right)$ with grid and combustor turbulence

The top figure shows the expected behavior for a turbulent boundary layer with a peak in turbulent kinetic energy emanating from the wall. The bottom figure shows a very different behavior. The combustor turbulence can be observed to penetrate deep into the boundary layer. In addition, at around $y / \delta=0.4$, combustor turbulence can be seen to be amplified by the boundary layer. This mechanism is the result of mean shear in the boundary layer stretching the eddies imposed into the boundary layer by the combustor turbulence and will be discussed in more detail later.

Figures 16 and 17 show the variation of skewness and kurtosis through the boundary layer. Skewness is a measure of the symmetry of the velocity fluctuations. A normal distribution has a skew factor of zero. Kurtosis is a measure of the width of the probability distribution of the velocity fluctuations and describes how outlier-prone a distribution is. A normal distribution has a kurtosis factor of 3 .

Figures 16 and 17 show that combustor turbulence dominates the velocity fluctuations throughout the boundary layer, down to very close to the wall. The trough in skew and peak in kurtosis, expected at the edge of the boundary layer in a normal turbulent boundary layer, have been completely removed by the combustor turbulence. In conclusion, the combustor turbulence penetrates down to close to the wall dominating the turbulent structure of the boundary layer.

\subsection{Cause of Increase in Dissipation}

Appendix B shows that viscous dissipation in a boundary layer is the result of one of two mechanisms:

$$
C_{D}=\frac{1}{U_{\infty}^{3}} \int_{0}^{\infty} \frac{\tau}{\rho} \frac{\partial U}{\partial y} d y+\frac{1}{U_{\infty}^{3}} \int_{0}^{\infty}-(\overline{u v}) \frac{\partial U}{\partial y} d y
$$

The first term is the viscous dissipation of kinetic energy from the mean field. The second term is the conversion of kinetic energy from the mean field to turbulent kinetic energy (production of turbulent kinetic energy).

The first term was measured, and the second term was deduced from the overall rise in $C_{D}$. The results at $R e_{\theta}=2,000$ are shown in Table 2. At this $R e_{\theta}$ the exact rise in $C_{D}$ due to the presence of combustor turbulence is $20.4 \%$. The cause of the rise can now be identified with Equation 5. Of the total rise, $68 \%$ is due to a rise in the viscous dissipation of kinetic energy from the mean field. This is due to the shape of the boundary layer changing, as shown in Figure 8 . The remaining $32 \%$ of the rise is due to a rise in the production of turbulent kinetic in the boundary layer. This can be seen from the peak in turbulent kinetic energy in the lower part of Figure 15.

Table 2: Components of $C_{D}$ for boundary layer at $\boldsymbol{R e}_{\theta}=2,000$

\begin{tabular}{|c|c|c|c|}
\hline & Grid Tu & Comb Tu & Relative Change \\
\hline$C_{D}$ & $1.576 \times 10^{-3}$ & $1.897 \times 10^{-3}$ & $+20.4 \%$ \\
\hline$C_{D}^{\text {mean }}$ & $0.627 \times 10^{-3}$ & $0.846 \times 10^{-3}$ & $+35 \%(68 \%$ of the rise $)$ \\
\hline$C_{D}^{\text {turb }}$ & $0.949 \times 10^{-3}$ & $1.051 \times 10^{-3}$ & $+11 \%(32 \%$ of the rise $)$ \\
\hline
\end{tabular}

\section{PROFILE LOSS}

Figure 7 shows that the presence of combustion causes the profile loss to rise by $37 \%$. The aim of this section is to show the development and physical cause of this increase.

\subsection{Attached Suction Surface Loss}

Figure 18 shows the development of loss along the rear of the suction surface measured using a hot-wire boundary layer probe. The loss coefficient was calculated from measurements of the blade energy thickness and static pressure coefficient.

$$
Y_{p}=\frac{\delta_{e}}{\sigma \cos \alpha_{2}} C_{p}^{3 / 2}
$$

A comparison of the blue and red points shows the impact of combustor turbulence on the development of loss. At the trailing edge, the presence of combustor turbulence raises the suction surface loss by $42 \%$.

To determine the shape of the development of loss for the grid turbulence case, MISES was used. The code is a coupled Euler boundary layer solver [30]. The MISES prediction is shown in Figure 18 as a red line. A comparison of the red points and red line shows that the two are in good agreement. This indicates that for the grid turbulence case the transition point is at $42 \%$ surface length. 


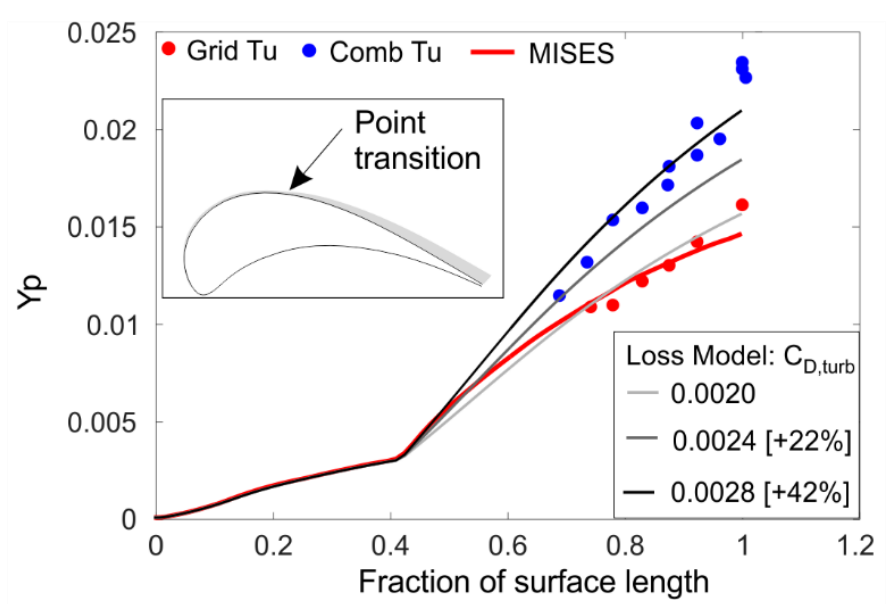

Figure 18: Suction surface loss on the blade in grid and combustor (measurements and calculations)

To help interpret the effect of changing dissipation coefficient on profile loss, a simple loss model was developed. The loss at each point on the surface was calculated using Equation 7.

$$
Y_{p}=\frac{2}{\sigma \cos \alpha_{2}} \int_{0}^{L_{s s}} C_{D}\left(C_{p}\right)^{3 / 2} d(s)
$$

In the laminar region of the model, $C_{D}$ was determined using the laminar correlation given by Schlichting [31]. Point transition was fixed at $42 \%$ surface length. For the case of combustor turbulence, it proved difficult to determine the exact location of transition. However, the transition did not seem to move significantly and was therefore fixed in the loss model. In the turbulent region, $C_{D}$ was fixed at a number of values. The specific values chosen will be discussed below.

In Figure 18, the loss model which most closely fits the red points is a turbulent $C_{D}=0.0020$. The agreement between the experimental measurements, MISES, and the loss model is surprisingly good.

In Figure 18, the loss model which most closely fits the blue points is a turbulent $C_{D}=0.00284$. This value of $C_{D}$ is $42 \%$ higher than the value which matched the grid turbulence data $\left(C_{D}=0.002\right)$. This is surprising, because in the flat plate tests, the presence of grid turbulence was found to raise $C_{D}$ by only $22 \%$. The loss model with a turbulent $C_{D}=0.00244$ represents the case where the $C_{D}$ is raised by $22 \%$.

In conclusion, the combustor turbulence causes a much larger increase in $C_{D}$ on the suction surface of the blade than on the flat plate $(42 \%$ compared to $22 \%)$. The cause of this rise will be discussed in a following section.

\subsection{Downstream Loss Development}

Figure 19 shows total pressure loss coefficient at the midspan exit of the turbine cascade control volume. The presence of combustor turbulence can be seen to significantly increase the wake width. The presence of combustor turbulence increases the mass-averaged loss by $37 \%$.

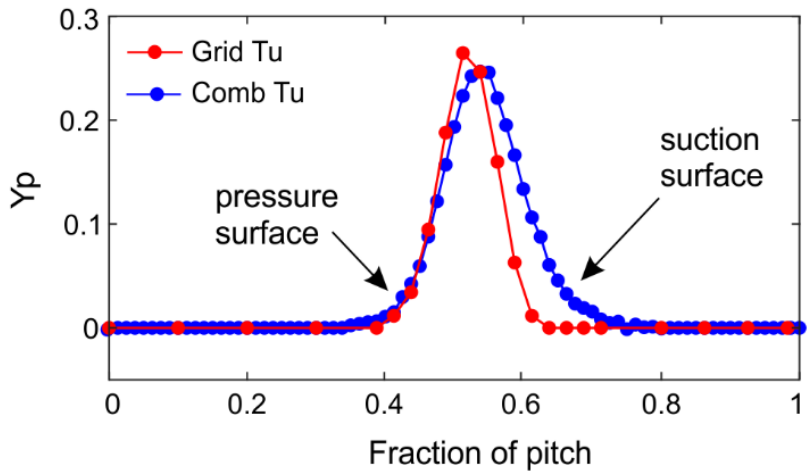

Figure 19: Total pressure loss coefficient measured at midspan exit of the turbine cascade $(1.21 \mathrm{Cx})$

Figure 20 shows the development of loss downstream of the cascade trailing edge. Just downstream of the trailing edge $(\mathrm{x}=1.03 \mathrm{Cx})$, the presence of combustor turbulence raises the loss by $40 \%$. This is close to the increase in suction surface loss of $42 \%$ shown in the previous section. At the exit of the turbine cascade control volume $(x=1.21 \mathrm{Cx})$, the presence of combustor turbulence raises the mass-averaged loss by $37 \%$ and the mixed out loss by $34 \%$.

In conclusion, the presence of combustor turbulence raises the attached loss by $40 \%$ and the mixed out loss by $34 \%$. The smaller rise in mixed out loss is a result of the change in the shape factor of the boundary layer at the suction surface trailing edge. The presence of combustor turbulence reduces the shape factor of the boundary layer and therefore reduces the downstream mixing loss.

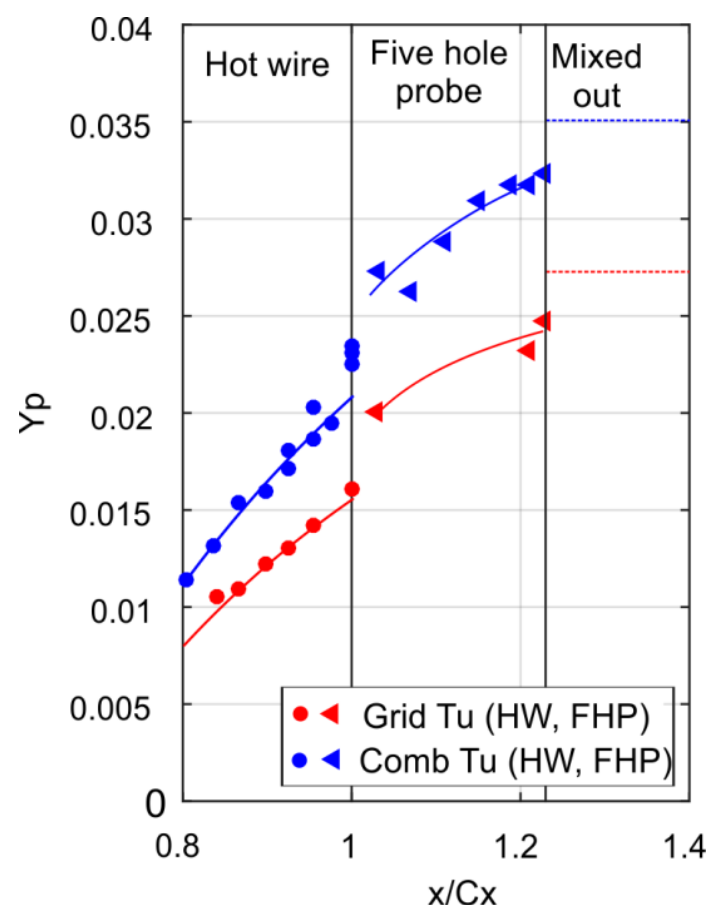

Figure 20: Development of mid-span loss coefficient just upstream and downstream of the blade trailing edge. 


\subsection{Physical Mechanism}

The power spectra of turbulent kinetic energy, measured at $98 \%$ suction surface, are shown in Figure 21. The figure should be compared with Figure 15.

First, compare the freestream in Figures $21 \mathrm{~b}$ and $15 \mathrm{~b}$. In the cascade case, the freestream power spectrum is much lower than in the flat plate case. This is due to acceleration of the freestream in the cascade, which decreases the streamwise fluctuations and reduces the turbulence intensity to $4 \%$ at the trailing edge.

Second, compare the boundary layers in Figures $21 \mathrm{~b}$ and Figure $15 \mathrm{~b}$. In the cascade case, the maximum magnitude of the power spectrum is more than twice that on the flat plate case. This shows that in the cascade case, the boundary layers have much higher levels of turbulent kinetic energy production than in the flat plate case. The rise in kinetic energy production is responsible for the larger than expected increase in the $C_{D}(42 \%$ for the cascade compared to $22 \%$ for the flat plate).

The rise in turbulent kinetic energy production is caused by diffusion of the boundary layer. A similar behavior can be observed in the case of grid turbulence by comparing Figure $27 \mathrm{a}$ and Figure 20a.

It might seem surprising that the impact on the boundary layer is large in the combustor turbulence case despite the freestream turbulence intensity dropping close to the trailing edge. The reason is that the combustor turbulence penetrates the boundary layer earlier on the blade surface and remains in the boundary layer. This turbulent kinetic energy then convects downstream towards the trailing edge. Boundary layer diffusion then results in the sharp rise in the turbulent production.
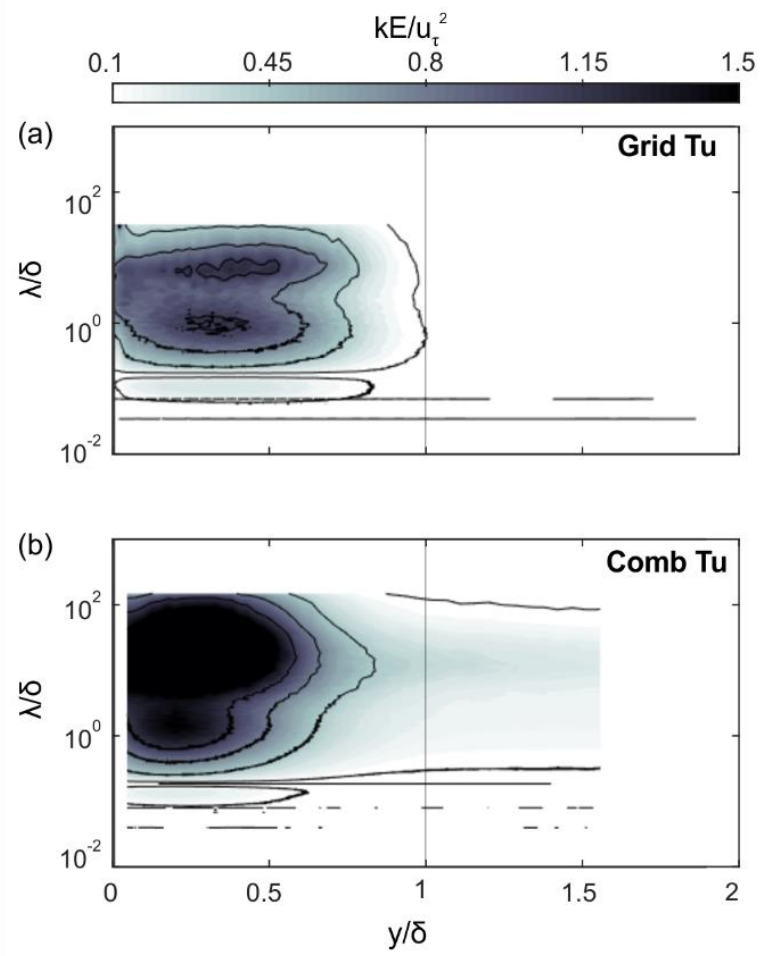

Figure 21: Power spectra of turbulent kinetic energy on the suction surface of the turbine cascade $(98 \%$ surface length).
In conclusion, the $42 \%$ rise in $C_{D}$ in the turbulent boundary on the suction surface is caused by the combined effects of combustor turbulence penetrating deep into the boundary layer and the subsequent diffusion of that boundary layer. This area of research requires further study but this finding implies that the presence of combustor turbulence will more severely penalize high lift designs of turbine blade.

\section{FREESTREAM LOSS}

Freestream loss is defined as the change in the total pressure, in the midspan freestream region between the inlet and exit of the turbine cascade control volume. The measured total pressure at each plane was mass-averaged only over the freestream region. For the grid turbulence and combustor turbulence cases, the freestream loss coefficients are $0 \%$ and $0.27 \%$, respectively. Figure 7 shows that the uncertainty in this loss measurement is high, $\pm 0.2 \%$. This is because demarcating the freestream is difficult in the case of combustor turbulence.

There are three possible causes of freestream loss. To understand these, consider flow in a pipe with inviscid walls and uniform mean inlet flow. The balance equation for the total pressure of the mean field, as described in Appendix A, is given by:

$$
\begin{aligned}
\dot{m} \Delta\left[\frac{P_{0}}{\rho}\right]=-\int_{\mathcal{V}}[ & \left.v\left(\frac{\partial U_{i}}{\partial x_{j}}+\frac{\partial U_{j}}{\partial x_{i}}\right) \frac{\partial U_{i}}{\partial x_{j}}\right] d \mathcal{V} \\
& -\int_{\mathcal{V}}\left[\left(-\overline{u_{\imath} u_{j}}\right) \frac{\partial U_{i}}{\partial x_{j}}\right] d \mathcal{V}-\dot{m} \Delta\left[\overline{u^{2}}\right]
\end{aligned}
$$

The three terms on the right hand side of the equation show possible sources of freestream loss. The first term on the right hand side represents the dissipation of mean field kinetic energy caused by the mixing out of velocity gradients. When combustor turbulence is generated, it is impossible to create a flow which does not have a velocity variation in the mean flow field. An upper bound on the magnitude of this term can be estimated by mixing out the mean field velocity variation at the inlet to the turbine cascade control volume. This gives a negligible change in loss coefficient of $0.01 \%$.

The second term on the right hand side of Equation 8 represents the conversion of mean field kinetic energy into turbulent kinetic energy. The turbulent vorticity is stretched by the mean strain. This transfers energy from the streamwise to the lateral components of turbulent kinetic energy. Overall, as the flow is accelerated through the cascade, this causes a rise in turbulence production. The magnitude of this term can be estimated using rapid distortion theory [32]. This term gives a change in loss coefficient of $+0.12 \%$.

The third term on the right hand side of Equation 8 represents a difference in the 'flow work' on the inlet and exit planes by the turbulent pressure (the isotropic Reynolds stress terms). These Reynolds stress terms are analogous to an additional pressure term acting on the inlet and exit of the control volume. The magnitude of the 'flow work' done by these terms can be estimated using the measured turbulent kinetic energy at the inlet and exit of the turbine cascade control volume. This 
gives a change in loss coefficient of $-0.32 \%$. The negative sign is due to the 'flow work' into the control volume being higher than out of the control volume.

The sum of these three terms gives a total freestream loss coefficient of $-0.2 \%$. This contrasts to the measured freestream loss coefficient of $+0.27 \%$. The free stream loss was therefore determined to be $0.47 \%$, which is shown in Table 1 . The cause of this difference is not understood and requires further study. However, we will show (Section 8) that a likely cause of this is due to combustor turbulence mixing boundary layer loss far into the freestream. This causes a difficulty in properly defining the freestream.

Though the cause of the positive freestream loss coefficient is not understood, it is important for this study to note that the size of the freestream loss is small compared to the changes in profile and endwall losses which are being measured.

\section{ENDWALL LOSS}

The endwall loss is calculated by subtracting the profile and freestream losses from the total loss. Figure 7 shows that the presence of combustion turbulence causes the endwall loss to rise by $38 \%$. The rise in endwall loss due to the presence of combustor turbulence could have two possible causes: a rise in the strength of the endwall secondary flow, or a rise in the
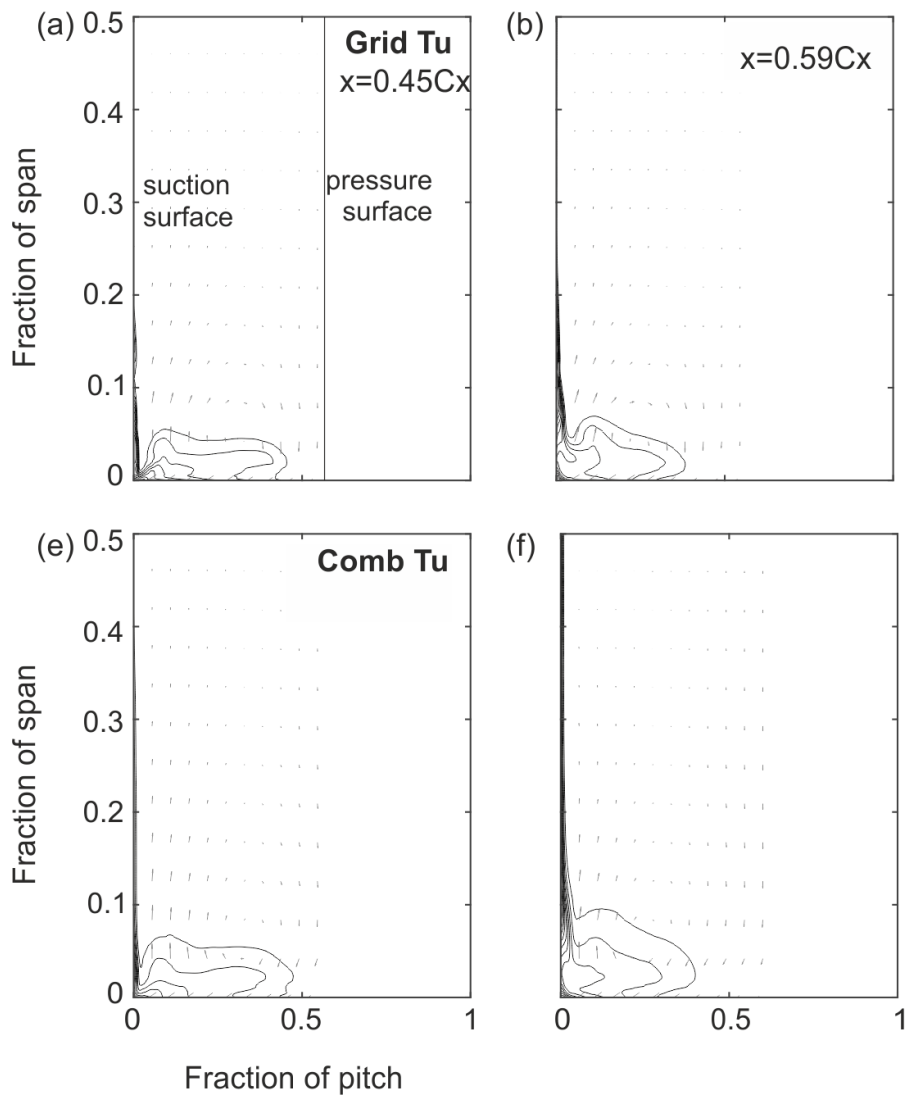

dissipation associated with the endwall secondary flow (but with the strength of the flow unchanged).

Coull [33] found that for a wide range of turbine designs, with the same inlet boundary layer, the magnitude of the endwall loss could be correlated with the strength of the secondary flow. In the two cases considered in this paper, the inlet boundary layers are relatively similar. The inlet boundary layer thicknesses are $6.3 \%$ and $8 \%$ of span for the grid and combustor case. The shape factors $\left(H_{12}\right)$ are 1.35 and 1.27 , respectively. Any significant change in strength of the endwall secondary flow must therefore be due to the presence of combustor turbulence.

To investigate the influence of combustor turbulence on the strength of the secondary flow, traverses were measured at four axial locations within the blade passage. Figure 22 shows contours of loss coefficient and secondary velocity vectors for both the case with grid turbulence and the case with combustor turbulence. The horizontal axis begins at the blade suction surface and is normalized by the blade to blade pitch $(230 \mathrm{~mm})$. The area of the passage is shown explicitly in the first subplot, where a solid line marks the pressure surface of the adjacent blade.

The relative strength of the secondary flow can be gauged by comparing the penetration depth of the suction surface separation line at each axial location. It can be seen that the penetration depths in the two cases are very similar. By $87 \%$ of
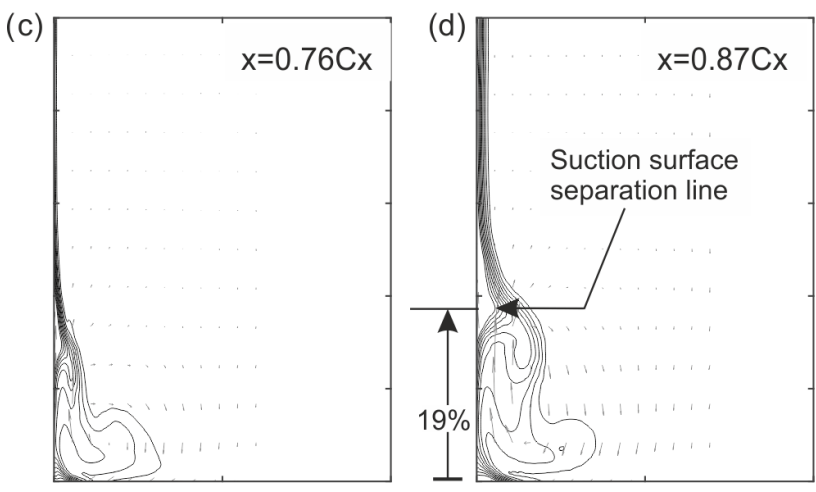

(g)
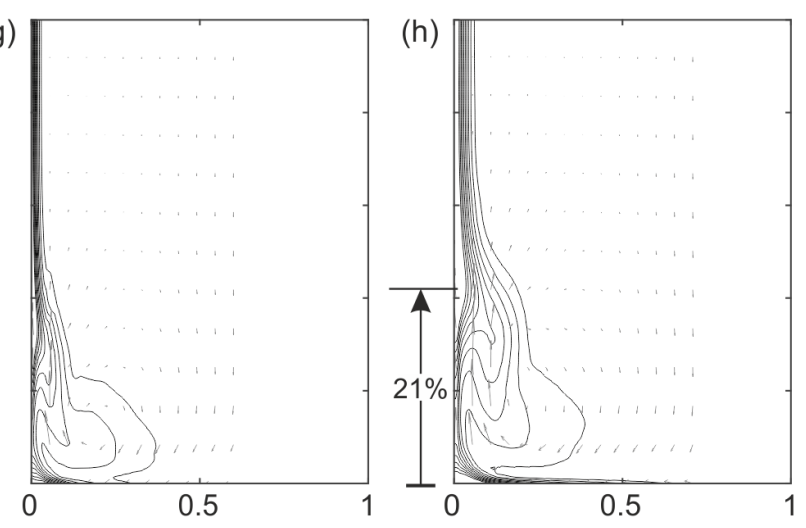

Figure 22: Contours of loss coefficient at four axial locations within the turbine cascade. First row is grid turbulence and second row is combustor turbulence. Contour intervals are $5 \%$ of exit dynamic head. 


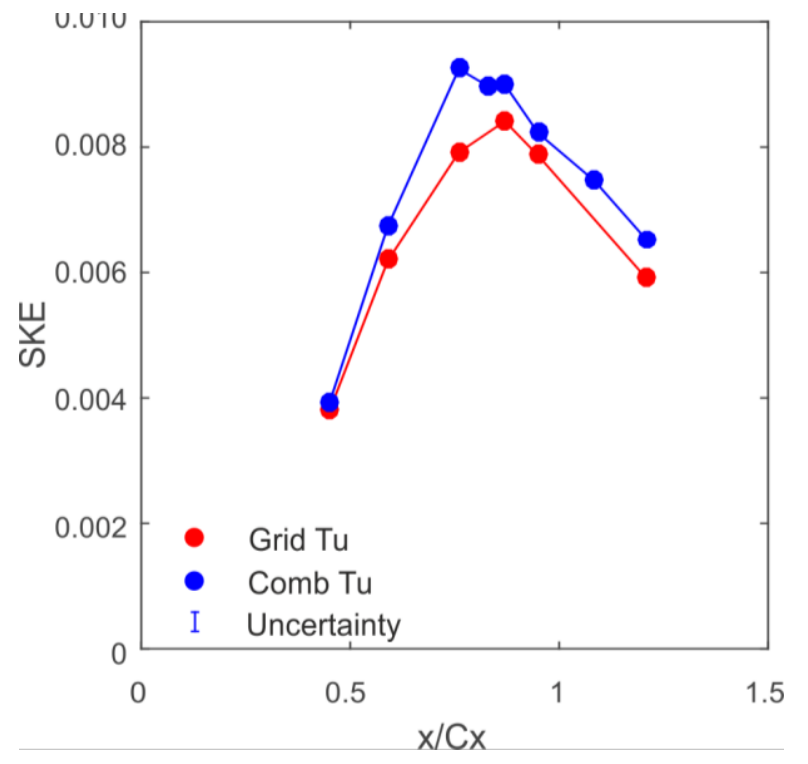

Figure 23: Mass-average secondary kinetic energy

axial chord $(0.87 \mathrm{Cx})$, the penetration depth of the suction surface separation line, for the case with combustor turbulence, is $2 \%$ of the span further from the endwall.

The strength of the secondary flow can also be determined by integrating the secondary kinetic energy on each traverse plane (using the definition given by [34]). A comparison for the two cases is shown in Figure 23. Once again, the presence of combustor turbulence can be seen to have only a small effect on the strength of the secondary flow.

The cause of the rise in endwall loss must therefore be due to a rise in dissipation in the endwall region. To determine the region of endwall in which this rise in dissipation occurs, the difference in the loss coefficient between the combustor turbulence case and grid turbulence case at $0.87 \mathrm{Cx}$ is plotted in Figure 24. Red regions show where the combustor turbulence case has higher loss, while blue denotes regions where the grid turbulence case has higher loss.

Figure 24 shows that combustor turbulence has higher loss in three regions of the endwall flow. The first region is a thicker endwall boundary layer. This region shows a large rise in loss coefficient, but the mass flow associated with the region is small; therefore, the contribution of this region to the rise in endwall loss is small. The second region is a rise in loss coefficient associated with endwall loss core. In this region, both the rise in loss coefficient and the mass flow are large, resulting in a significant contribution to the rise in endwall loss. The third region is the rise in loss in the freestream. The rise in loss coefficient in this region is relatively small, but the mass flow associated with it is very large. The contribution of this region to the rise in endwall loss is correspondingly significant.

This last region, the rise in loss in the freestream, is interesting. It implies that combustor turbulence mixes boundary layer fluid far into the freestream. This explains the difficulty in extracting the freestream loss in the previous section of the paper.

We are now in a position to give a probable cause of the rise

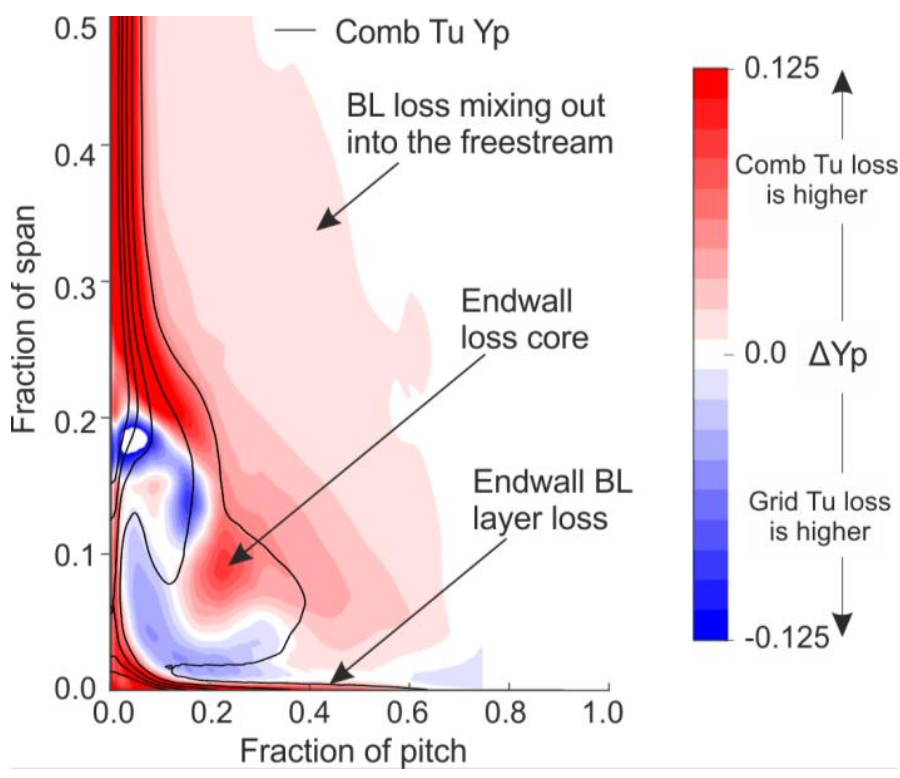

Figure 24: Change in loss coefficient due to combustor turbulence at $0.87 \mathrm{Cx}$

in endwall loss. Conventionally, endwall loss is considered to correlate with the strength of the secondary flow. In the case of combustor turbulence, the secondary flow strength is unchanged but endwall loss rises. To understand why, the loss mechanism responsible for endwall loss must be understood. The secondary flow itself is an inviscid phenomenon, resulting from the turning and stretching of vorticity in the inlet boundary layer. Very little of the endwall loss is a direct result of the dissipation of this secondary kinetic energy. Instead endwall loss is largely the result of the secondary flow sweeping the boundary layer off of the blade and endwall surfaces and being replaced by a new boundary layer. Therefore, a possible explanation of the rise in endwall loss is that, for a fixed strength of secondary flow, the endwall loss scales with the dissipation coefficient of the boundary layer which is being swept off the blade and endwall surfaces. This would explain why the rise in the endwall loss $(+38 \%)$ is similar in magnitude to the rise in profile loss $(+37 \%)$. It should, however, be noted that without measuring the local dissipation coefficient throughout the endwall boundary layer and the freestream, this conclusion cannot be verified.

\section{INDUSTRIAL IMPLICATIONS}

It is important to understand the impact of the loss mechanisms discussed in this paper on the efficiency of a turbine stage mounted downstream of a combustor. Two cases will be considered: a low speed stage, based on the current cascade, and a high speed stage representative of a modern engine.

For the case of a low speed stage, a 50\% reaction stage with identical stator and rotor profiles was assumed. This is similar to the computational study of Denton and Pullan [22]. It was assumed that combustor turbulence affects only the stator row of the turbine stage. Therefore, the increase in loss measured in the cascade blade was applied to the stator row, with the rotor loss 
left unchanged. The presence of combustor turbulence was found to reduce the stage efficiency by $1.1 \%$.

For the case of the engine representative stage, the profile loss of the vane was determined using MISES. Under the presence of combustor turbulence, the transition location was assumed to be unchanged, but the dissipation coefficient in the turbulent region of the boundary layer was raised by $42 \%$. The baseline endwall loss was deduced from an engine correlation. It was then increased by $38 \%$ based on the findings from this research.

It was assumed that the fractional rise in endwall loss was the same as for the low speed blade used in this study. The freestream loss shown in Figure 7 was added. The engine cooling losses were assumed unchanged by the presence of combustor turbulence. The presence of combustor turbulence on the vane alone was found to reduce the stage efficiency by $1.3 \%$. The larger reduction in stage efficiency on the engine representative stage, relative to the low speed stage, was due to differences in velocity profile of the blade and the transition location.

The magnitude of this drop in stage efficiency is very large. Some may ask, if the size of this efficiency drop is so large, why has it not been identified in real engines? The reason is twofold. First, the high speed turbine test facilities that are used to measure loss trades do not include combustors turbulence generators and therefore would not exhibit this effect. Second, the hostile environments in real engines make accurate measurement of the efficiency of the high pressure stage impossible. This means that the uncertainty of the efficiency measurement of the real high pressure stage is very high.

\section{CONCLUSIONS}

This paper has shown that the presence of combustor turbulence is very different in nature to the presence of grid turbulence. By the vane inlet the combustor turbulence is close to isotropic in nature. The turbulence penetrates deep into the boundary layer. This reduced the shape factor of the boundary layer. The mean shear in the boundary layer acts to stretch the turbulence resulting in a rise in the production of turbulent kinetic energy within the boundary layer. The combined result is that, in a zero pressure gradient, the presence of combustor turbulence causes a rise in dissipation coefficient of $22 \%$.

In a turbine cascade, the presence of combustor turbulence was measured to cause a $47 \%$ rise in total loss. This resulted from a $37 \%$ rise in profile loss and a $38 \%$ rise in endwall loss. When these loss mechanisms were applied to the vane from an engine representative high pressure stage, it was found to result in a $1.3 \%$ reduction in stage efficiency. This is an incredibly large number, and it is important that this new mechanism is included in turbine design systems.

Combustor turbulence is an incredibly difficult environment in which to make accurate loss measurements. The aim of this paper has therefore been to bring certainty to this difficult area of research and to provide a methodology on which future researchers can build. The research also acted to frame a number of important future research questions. How do adverse pressure gradients alter the dissipation coefficient of a turbulent boundary layer? If a turbulence intensity of $4 \%$ has no effect on the dissipation coefficient of a turbulent boundary layer, and a turbulence intensity of $10 \%$ increases the dissipation coefficient of a turbulent boundary layer by $22 \%$, what is the relationship between dissipation coefficient and turbulence intensity?

Finally, the research has significant implications for design. The type of combustor (lean burn or conventional) is likely to change the nature and intensity of the turbulence entering the high pressure turbine. In addition, it is likely that the loading distribution of the vane will change the impact of combustor turbulence on loss, because the impact of combustor turbulence is highly dependent on the location of transition and the magnitude of the adverse pressure gradient to which the boundary layer is subjected.

\section{ACKNOWLEDGEMENTS}

The authors would like to gratefully acknowledge the funding from Rolls-Royce and EPSRC. A special thanks to Bill Cummings and Jon Ebacher in RRC, Fred Goenaga, Mark Stokes, and Simon Gallimore in RR plc, and Andrew Wheeler, Peter Davidson, and Nick Cumpsty in Cambridge for their support and technical supervision.

\section{NOMENCLATURE}

\begin{tabular}{|c|c|c|}
\hline$C_{D}$ & Dissipation coefficient & \\
\hline$C_{f}$ & Skin friction coefficient & \\
\hline$C_{p}$ & Cascade loading & $=\frac{P_{o 1}-P}{P_{o 1}-P_{2}}$ \\
\hline$C_{x}$ & Axial chord & \\
\hline$E$ & Streamwise velocity pow & er spectral density \\
\hline$f$ & Frequency & \\
\hline$H_{12}$ & Shape factor & $=\frac{\delta^{*}}{\theta}$ \\
\hline$H_{23}$ & Shape factor & $=\frac{\theta}{\delta_{e}}$ \\
\hline KF & Kurtosis factor & $=\overline{u^{4}} /\left(\overline{u^{2}}\right)^{4 / 2}$ \\
\hline$\dot{m}$ & Mass flow rate & \\
\hline$P_{o}$ & Total pressure & \\
\hline$P$ & Static pressure & \\
\hline$R e_{\theta}$ & $\begin{array}{l}\text { Boundary layer } \\
\text { Reynolds number }\end{array}$ & $=U_{\infty} \theta / v$ \\
\hline$S F$ & Skew factor & $=\overline{u^{3}} /\left(\overline{u^{2}}\right)^{3 / 2}$ \\
\hline Tu & Turbulence intensity & $=\sqrt{\overline{\overline{u^{2}}}} / U$ \\
\hline$\widetilde{U}$ & Instantaneous velocity & $\widetilde{U}(t)=U+u$ \\
\hline$U, V$ & $\begin{array}{l}\text { Time average flow } \\
\text { velocity }\end{array}$ & \\
\hline$u, v$ & Fluctuating velocity & $=\widetilde{U}(t)-U$ \\
\hline$u_{\tau}$ & Shear stress velocity & \\
\hline $\mathcal{v}$ & Volume & \\
\hline$c, y, z$ & Flow coordinates & \\
\hline$Y_{p}$ & $\begin{array}{l}\text { Total pressure loss } \\
\text { coefficient }\end{array}$ & $=\frac{P_{01}-P_{02}}{P_{01}-P_{2}}$ \\
\hline
\end{tabular}




\begin{tabular}{|c|c|c|}
\hline \multicolumn{3}{|c|}{ Greek Symbols } \\
\hline$\alpha$ & Cascade flow angle & \\
\hline$\delta, \delta_{99}$ & Boundary layer thickness & \\
\hline$\delta^{*}$ & Displacement thickness & $\left(1-\frac{}{U I}\right) d y$ \\
\hline$\delta_{e}$ & Energy thickness & $=\frac{}{U_{m}}\left(1-\frac{\overline{U^{2}}}{2}\right.$ \\
\hline$\theta$ & Momentum thickness & $=\frac{\sigma}{U_{0}}\left(1-\frac{\sigma}{U_{m}}\right.$ \\
\hline$\kappa$ & Wave number & $=2 \pi f / U$ \\
\hline$\lambda$ & Wave length & $=2 \pi / \kappa$ \\
\hline$\mu$ & Viscosity of air & \\
\hline$v$ & Kinematic viscosity of air & \\
\hline$v_{t}$ & Apparent turbulent viscosit & \\
\hline$\rho$ & Density of air & \\
\hline$\sigma$ & Cascade pitch & \\
\hline$\tau$ & Shear stress & $=\mu(\partial U / \partial y)$ \\
\hline$\omega$ & Frequency & \\
\hline
\end{tabular}

\section{Subscripts}

$\begin{array}{cl}\infty & \text { Edge of the boundary layer } \\ 1 & \text { Turbine inlet } \\ 2 & \text { Turbine exit }\end{array}$

\section{REFERENCES}

[1] Zimmerman, D.R., 1979. "Laser anemometer measurements at the exit of a T63-C20 combustor." NASA CR-159623.

[2] Seasholtz, R.G., Oberle, L.G., and Weikle D.H., 1983. "Laser anemometry for hot section applications." NASA CP-2289, pp.57-67.

[3] Cha, C. M., Hong, S., Ireland, P. T., Denman, P., and Savarianandam, V., 2012. "Turbulence levels are high at the combustor-turbine interface." ASME Paper GT2012-69130.

[4] Denton J. D., 1993. "The 1993 IGTI Scholar Lecture: Loss mechanisms in turbomachines." ASME. Journal of Turbomachinery, 115(4):621-656.

[5] Ames, F. E., and Moffat, R. J., 1990, "Heat transfer with high intensity, large scale turbulence: the flat plate turbulent boundary layer and the cylindrical stagnation point." Report No. HMT-44, Thermosciences Division of Mechanical Engineering, Stanford University.

[6] Thole K. A., and Bogard D. G., 1995. "Enhanced heat transfer and shear stress due to high free-stream turbulence." ASME Journal of Turbomachinery, 117(3), pp.418-424.

[7] Ames, F.E. and Plesniak M.W., 1997. "The influence of large-scale, high-intensity turbulence on vane aerodynamic losses, wake growth, and the exit turbulence parameters." ASME Journal of Turbomachinery, 119(2), pp.182-192.

[8] Ames, F. E., 1998. "Aspects of vane film cooling with high turbulence, part II, adiabatic effectiveness." ASME Journal of Turbomachinery, 120, pp.768-776.

[9] Bons, J. P., 2002. "St and cf augmentation for real turbine roughness with elevated freestream turbulence." ASME Journal of Turbomachinery, 124, pp.623-644.
[10] Stefes, B. and Fernholz, H. H., 2003. "Skin friction and turbulence measurements in a boundary layer with zeropressure-gradient under the influence of high intensity freestream turbulence." European Journal of Mechanics B/Fluids, 23, pp. 303-318.

[11] Chowdhury, N.H.K., Dey, P.K., and Ames, F.E., 2011, “The influence of inlet contraction on vane aerodynamic losses and secondary flows with variable turbulence and Reynolds number," ASME Paper No. GT2011-45737.

[12] Martin, D., and Thorpe, S.J., 2012. "Experiments on combustor effusion cooling under conditions of very high freestream turbulence.' ASME Paper GT2012-68863.

[13] Kingery, J.A., and Ames, F.E., 2015, "Stagnation region heat transfer augmentation at very high turbulence levels," ASME Journal of Turbomachinery, 138 (8).

[14] Hancock P.E., and Bradshaw P.P. (1983). The effect of freestream turbulence on turbulent boundary layers. ASME Journal of Fluids Engineering, 105(3):284-289. doi:10.1115/1.3240989.

[15] Castro I.P., 1984. "Effects of free stream turbulence on low Reynolds number boundary layers." ASME Journal of Fluids Engineering, 106(3), 298-306.

[16] Thole, K. A. and Bogard, D. G., 1996. "High freestream turbulence effects on turbulent boundary layers." ASME Journal of Fluids Engineering, 118, pp.276-284.

[17] Sharp, N., Neuscamman, S., and Warhaft, Z., 2009. "Effects of large-scale free stream turbulence on a turbulent boundary layer." Physics of Fluids. 21(9).

[18] Dogan, E., Hanson, R., and Ganapathisubramani, B., 2016. "Interactions of large-scale free-stream turbulence with turbulent boundary layers." Journal of Fluid Mechanics, 802, pp.79-107.

[19] Roach, P. E., 1987. "The generation of nearly isotropic turbulence by means of grids." International Journal of Heat and Fluid Flow, 8(2), pp.82-92.

[20] Harrison, S., 1989. "The Influence of Blade Stacking on Turbine Loss." PhD thesis, Cambridge University.

[21] Harrison,S., 1989. "Secondary loss generation in a linear cascade of high turning turbine blades." ASME paper 89-GT47.1989.

[22] Denton, J., and Pullan, G., 2012. “A numerical investigation into the sources of endwall loss in axial flow turbines." ASME Paper GT2012-69173.

[23] Grewe, R., Miller, R.J., Hodson, H.P., 2014. "The effect of endwall manufacturing variations on turbine performance." ASME Paper GT2014-25326.

[24] Rodríguez-López, E., Bruce, P.J.K., Buxton, O.R.H., 2015. "A robust post-processing method to determine skin friction in turbulent boundary layers from the velocity profile." Experiments in Fluids 56(4):68.

[25] Esteban, L.B., Dogan, E., Rodríguez-López, E., Ganapathisubramani, B., 2017. "Skin-friction measurements in a turbulent boundary layer under the influence of free-stream turbulence." Experiments in Fluids 58:115.

[26] Goldstein, S., 1936. "A note on the measurement of total head and static pressure in a turbulent stream." Proceedings of the Royal Society of London, 155A. 
[27] Bailey, S. C. C., Hultmark, M., Monty, J. P., Alfredsson, P. H., Chong, M. S., Duncan, R. D., Fransson, J. H. M., et al., 2013. "Obtaining accurate mean velocity measurements in high Reynolds number turbulent boundary layers using Pitot tubes." Journal of Fluid Mechanics, 715.

[28] Telionis, D. P., 1979. "Review - Unsteady boundary layers, separated and attached." Journal of Fluids Engineering, 101(1).

[29] Schlatter P., and Orlu R., 2010, “Assessment of direct numerical simulation data of turbulent boundary layers.” Journal of Fluid Mechanichs, 659, 116-126.

[30] Drela, M. and Youngren, H., 2008. A user's guide to MISES 2.63 .

[31] Schlichting, H., 1968. Boundary-Layer Theory. McGraw Hill.

[32] Batchelor, G. K., 1953. The theory of homogenous turbulence. Cambridge Science Classics.

[33] Coull, J.D., Private communication.

[34] Gregory-Smith, D. G., Graves, C. P., and Walsh, J. A., 1988. "Growth of secondary losses and vorticity in an axial turbine cascade." Journal of Turbomachinery, 110(1), 1-8.

[35] Hinze, J.O., 1975. Turbulence. McGraw Hill.

\section{APPENNDIX A: KINETIC ENERGY OF THE MEAN FLOW}

The purpose of this section is to derive a transport equation for the kinetic energy of the mean flow field and explain the significance of each term. For steady incompressible flow the mean field kinetic energy balance is written in Equation A1 in index notation following Hinze [35].

$$
\begin{aligned}
\frac{\partial}{\partial x_{i}} U_{i}\left(\frac{P}{\rho}+\frac{1}{2} U_{j} U_{j}\right) & -v \frac{\partial}{\partial x_{i}} U_{j}\left(\frac{\partial U_{i}}{\partial x_{j}}+\frac{\partial U_{j}}{\partial x_{i}}\right) \\
+ & \frac{\partial}{\partial x_{j}}\left[\left(\overline{u_{\imath} u_{j}}\right) U_{i}\right] \\
= & -v\left(\frac{\partial U_{i}}{\partial x_{j}}+\frac{\partial U_{j}}{\partial x_{i}}\right) \frac{\partial U_{i}}{\partial x_{j}} \\
+ & \left(\overline{u_{\imath} u_{j}}\right) \frac{\partial U_{i}}{\partial x_{j}}
\end{aligned}
$$

The first term on the left hand side is the change in flow work and change in kinetic energy flux across the element. The second term on the left hand size is the viscous work done on the boundary of the element. The third term on the left hand side is the work down on the element by Reynolds stresses. The two terms on the right hand side represent what is known as the dissipation of kinetic energy from the mean field. The first term is viscous dissipation of kinetic energy from the mean field. The second term is the transfer of mean field kinetic energy into turbulent kinetic energy (turbulence production). The term represents the work of deformation by the turbulence stresses per unit of mass and of time.

We now consider a finite control volume with a single uniform inlet and exit aligned perpendicular to the x-direction.
The flow is incompressible. Integrating Equation A1, assuming the control volume is adiabatic with zero work, yields:

$$
\dot{m} \Delta\left[\frac{P}{\bar{\rho}}+\frac{1}{2} U^{2}\right]=-D-\dot{m} \Delta\left[\overline{u^{2}}\right]
$$

Where dissipation is defined as

$$
D=\int_{\mathcal{V}}\left(v\left(\frac{\partial U_{i}}{\partial x_{j}}+\frac{\partial U_{j}}{\partial x_{i}}\right) \frac{\partial U_{i}}{\partial x_{j}}+\left(-\overline{u_{\imath} u_{\jmath}}\right) \frac{\partial U_{i}}{\partial x_{j}}\right) d \mathcal{V}
$$

If there are no gradients of the mean velocity, the dissipation term is zero and the mean kinetic energy equation is:

$$
\frac{P}{\bar{\rho}}+\frac{1}{2} U^{2}+\overline{u^{2}}=\text { const. }
$$

\section{APPENDIX B: KINETIC ENERGY INTEGRAL BOUNDARY LAYER EQUATION}

For cases where the freestream turbulence is high, the kinetic energy integral equation contains a number of extra terms compared to the form of the equation for low freestream turbulence The aim of this section is to show the form and physical meaning of these extra terms.

The mean field kinetic energy integral equation for a $2 \mathrm{D}$ boundary layer in zero pressure gradient is given by Hinze [35]:

$$
\begin{aligned}
\frac{1}{2} \frac{\partial \delta_{e}}{\partial x}-\frac{\partial}{\partial x} \int_{0}^{\infty}( & \frac{U}{U_{\infty}^{3}}(\overline{v v})+\frac{U}{U_{\infty}^{3}}(\overline{u u}) \\
& \left.+\frac{V}{U_{\infty}^{3}}(\overline{u v})\right) \partial y-\frac{(\overline{u v})_{\infty}}{\bar{U}_{\infty}^{2}}=C_{D}
\end{aligned}
$$

Where $C_{D}$ is dissipation coefficient of the boundary layer:

$$
C_{D}=\frac{1}{U_{\infty}^{3}} \int_{0}^{\infty} \frac{\tau}{\rho} \frac{\partial U}{\partial y} d y+\frac{1}{U_{\infty}^{3}} \int_{0}^{\infty}-(\overline{u v}) \frac{\partial U}{\partial y} d y
$$

Before discussing the physical meaning of the terms in the equations, it is worth considering the more common form of the kinetic energy integral equation which applies to cases of low freestream turbulence. For such cases, the third term on the left hand side of Equation B2 is zero, because $(\overline{u v})_{\infty}$ is small in the freestream. The second term on the left hand side of Equation B2 is also small because, in most practical cases, the boundary layer is considered to be in equilibrium. For low freestream turbulence Equation B2 can therefore be simplified as:

$$
\frac{1}{2} \frac{d \delta_{e}}{d x}=C_{D}
$$

Comparing the kinetic energy integral equation for low and high turbulence, it is clear that two extra terms exist. The first term is: 


$$
\frac{\partial}{\partial x} \int_{0}^{\infty}\left(\frac{U}{U_{\infty}^{3}}(\overline{v v})+\frac{U}{U_{\infty}^{3}}(\overline{u u})+\frac{V}{U_{\infty}^{3}}(\overline{u v})\right) \partial y
$$

The term represents the work on the inlet and exit boundaries of the control volume by Reynolds stresses. These terms can be thought of as analogous to flow work. In other words, the Reynolds stresses can be thought of as analogous to an extra pressure acting on the inlet and exit of the control volume. In cases of high freestream turbulence the turbulence decays in a streamwise direction and therefore this term is unbalanced and non-zero.

The second term is:

$$
-\frac{(\overline{u v})_{\infty}}{U_{\infty}^{2}}
$$

This term represents the work on the outer boundary of the control volume by Reynolds stresses. The term can be thought of as analogous to the work down by a shear force acting on a moving surface.

A similar analysis as shown above can be carried out for the momentum integral equation. For low freestream turbulence the momentum integral equation may be written as

$$
2 \frac{d \theta}{d x}=C_{f}
$$

In high free stream turbulence, additional terms also appear. For brevity this will not be shown here. For the derivation and the full equation in high free stream turbulence, the reader is referred to $[5]$.

\section{APPENDIX C: PRACTICAL MEASUREMENT OF DISSIPATION COEFFICIENT}

The major difference between analyzing boundary layers in grid and combustor freestream turbulence is the sensitivity of the analysis to the control volume which is chosen. When grid turbulence is present, the analysis of boundary layer measurements is insensitive to the location of the outer edge of the control volume, as long as it is located outside the boundary layer. When combustor turbulence is present, the analysis of the boundary layer measurement can become highly sensitive to the control volume that is chosen.

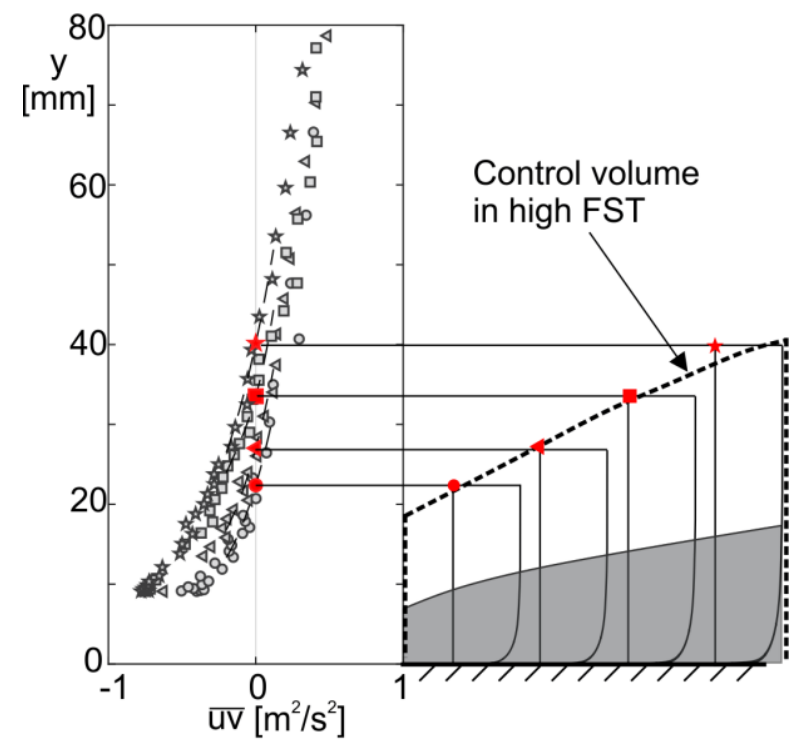

Figure C1: Definition of the control volume height for combustor turbulence case: (LHS) Measurements of $\overline{\mathbf{u v}}$ (RHS) Schematic of control volume.

The reason for this sensitivity can be seen by looking at Equation B2. For combustor turbulence, $\overline{u v}$ is non-zero in the freestream, so momentum is transferred between streamlines in the freestream. It is therefore important that, for whatever shape of control volume is chosen, the value of $\overline{u v}$ is known on the outer edge of the control volume. Figure $\mathrm{C} 1$ shows the variation of $\overline{u v}$ away from the surface of the flat plate between 200 and $450 \mathrm{~mm}$ downstream of the leading edge. In the freestream ( $\mathrm{y}>$ $70 \mathrm{~mm}), \overline{u v}$ is positive. As we approach the wall $(40 \mathrm{~mm}<\mathrm{y}<$ $70 \mathrm{~mm}$ ), $\overline{u v}$ drops. A convenient definition of the control volume outer edge is to define it along the line of $\overline{u v}=0$. This is shown on the right hand side of Figure $\mathrm{C} 1$. This definition of control volume was found to result in an extremely accurate balance of the momentum integral equation. It is used in this paper for all boundary layer measurements made in the presence of combustor turbulence. 